\title{
Prevalence and Foot Intrinsic Associated Factors of Ankle Sprains among a Random Sample of Tunisian Athletes: Across-Sectional Study
}

Emna Taghouti ( $\nabla$ emnataghouti9@gmail.com )

Faculty of Medicine of Sousse https://orcid.org/0000-0003-3390-8739

Meriam Gallas

Higher School of Health Sciences and Techniques

Hana Maatoug

Higher Institute of Sport and Physical Education of Sfax

Faycel Khachnaoui

University Hospital of Sahloul Sousse

\section{Research}

Keywords: Ankle sprain, athletes, ankle instability, prevalence, intrinsic factors, foot

Posted Date: December 8th, 2020

DOI: https://doi.org/10.21203/rs.3.rs-121787/v1

License: (c) (i) This work is licensed under a Creative Commons Attribution 4.0 International License. Read Full License 


\section{Abstract}

\section{Objective}

To determine the prevalence of ankle sprains and its associated factors in athletes.

\section{Methods}

This was a cross sectional descriptive study conducted among a random sample of 107 athletes. The subjects were recruited from 6 different associations in Sousse, Tunisia. Demographic, medical and foot characteristics were collected using a medical file completed by a validated, self administered questionnaire to verify ankle instability. All components of this study were approved by a research ethic committee, and all participants gave informed consent at every stage. Data entry and analysis were performed using SPSS 20 Software. The level of significance was set at $p<0.05$.

\section{Results}

The prevalence of ankle sprain was $71 \%$. The associated factors were; the weight $(p=0.033)$, the type of sport $(p=0.038)$, the profile of the athlete $(p=0.006)$, the unipodal static balance $(p=0.006)$, the limitation of the joint mobility $\left(p=10^{-6}\right)$, the ligament laxity $(p<0.05)$, the muscular force especially the eversor muscle (the long fibular) $(p<0.05)$ and the inversor muscle (the posterior tibial) $(p<0.05)$ and the ankle instability $(p<0.05)$.

\section{Conclusion}

Ankle sprains remain a frequent trauma in Tunisia. This injury must be taken into consideration and treated with a multidisciplinary approach (physicians, podiatrists, physiotherapists and physical trainers...) in order to lower its occurrence.

\section{Introduction}

Ankle sprain is the most common injury in sports. In France, its prevalence varies between $15 \%$ and $45 \%$ [1]. In the United States, its incidence is estimated at 6445 injuries per year [2] and the cost of treatment reached about $1008 \$$ for lateral injuries and $914 \$$ for medial ones [3].

This injury affects mainly the lateral ligament of the ankle causing thus either a simple distension (benign sprain) or a partial total tear (moderate or severe sprain) and more rarely the medial deltoid ligament [4]. It occurs when the foot violently bascule in inversion or eversion during a false step or in the brutal reception of the foot during a parachute jump [4].

Its appearance can be linked to several factors divided into intrinsic factors such as the musculoskeletal system, the ligament system, the joint mobility, and the proprioceptive foot receptors and extrinsic factors such as the athletes' footwear, frequency of training, type of gait, and the types of fields (ground) [5-6]. 
It can cause a temporary cessation of sport activity whose rest period varies according to its severity and even after resumption; the athlete may suffer from multiple discomforts such as: ankle chronic instability, ligament laxity, chronic pain, muscular weakness [8]. These manifestations can affect his sport activity, performance, posture, gait and even activities of daily life [7].

Despite its frequency of occurrence, the severity of its sequelae and its ability to influence the athlete's life, the prevalence of ankle sprain remains unknown in Tunisia. Therefore the objective of this study was to determine the prevalence of ankle sprain in athletes and its associated factors.

\section{Methods}

\section{Type, period and places of the study}

A cross sectional descriptive study was conducted over a period of 4 months in 6 sport associations in the region of Sousse, Tunisia.

\section{Participants}

We randomly selected 107 participants based on a proportional sampling from 6 different sport types. We included in this study athletes playing football, handball, volleyball, basketball, and tennis or running who gave their consent to participate in the study and who has a period of sports activity equal to or greater than 1 year.

\section{Data collection}

Data were carried out from the compilation of two sources of information. On one hand, a clinical file designed for foot and ankle examination. On the second hand, a validated self- administered questionnaire "The Cumberland Ankle Instability Tool" or the CAIT used to verify ankle instability [7-8].

The clinical file contained basic information related to anthropometric data such as; age, gender, height, weight and body mass index. Then sport data (type of sport, years of practice, profile, regularity and techniques of preparation for exercise: warming up, stretching...

Participants were asked about the injuries they had suffered from during their sport career (fractures, tendonitis, dislocations and ankle sprains...).

The index of Hernandez Corvo was used to determine the type of foot (flat, cavus)[9-10], The unipodal test served to evaluate static balance [11-12]. Ligament laxity was assessed using the method of varus and valgus stress test and with the anterior drawer test. Muscular force was tested by global and analytical testing [13].

\section{Data analysis}


Data entry and analysis were performed using SPSS 20 Software. Basic descriptive statistics (percentage, frequencies, etc.) were obtained for all participants by group. Differences were declared significant

at the 0.05 level (i.e., when $\mathrm{P}<0: 05)$.

\section{Results}

\section{- Descriptive results}

Among the 107 athletes recruited in the study, 71 were males (66.4\%) and 36 were females $(33.6 \%)$ with a mean (SD) age of $19.36(4.24)$ years.

Table 1 shows the distribution of the athletes by type of sport.

Table 1

The different type of sports

\begin{tabular}{|c|c|c|}
\hline \multicolumn{3}{|c|}{$\begin{array}{c}\text { Table } 1 \\
\text { The different type of sports }\end{array}$} \\
\hline Sport types & Effectif (n) & Pourcentage (\%) \\
\hline Football & 20 & 18.7 \\
\hline Basketball & 29 & 27.1 \\
\hline Handball & 16 & 15 \\
\hline Course & 23 & 21.5 \\
\hline Tennis & 13 & 12,1 \\
\hline Volleyball & 6 & 5.6 \\
\hline Total & 107 & $100 \%$ \\
\hline
\end{tabular}

\section{Prevalence}

The occurrence of sprain ankle in our sample was about $71 \%$ (76 athletes). Among our 76 athletes with ankle sprains, 93 ankles were affected by this trauma in which 51 were right ankles and 42 were left. Unilateral exposure was more frequent with a percentage of $77.6 \%$ compared to the bilateral exposure that represented $22.4 \%$.

- Analytic results

\section{Anthropometric factors}

The anthropometric data showed that no differences were found between the injured and uninjured groups in terms of gender, age, height and body mass index (BMI). Significant differences were found only in weight $(p=0.033)$. 
Table 2 depicts the full results. The $p$ values for each factor are presented as well.

Table 2

Anthropometric data for injured and uninjured athletes

\begin{tabular}{|c|c|c|c|c|c|}
\hline & \multicolumn{2}{|c|}{ Injured } & \multicolumn{2}{|c|}{ Uninjured } & \multirow[b]{2}{*}{$P$} \\
\hline & (n) & $(\%)$ & (n) & $(\%)$ & \\
\hline \multicolumn{6}{|l|}{ Gender } \\
\hline Male & 49 & 45.8 & 22 & 20.6 & \multirow[t]{2}{*}{0.653} \\
\hline Female & 27 & 25.2 & 9 & 8.4 & \\
\hline \multicolumn{6}{|l|}{ Age } \\
\hline$<19$ ys & 42 & 39.2 & 17 & 15.9 & \multirow[t]{2}{*}{1.00} \\
\hline$\geq 19$ ys & 34 & 31.8 & 14 & 13.1 & \\
\hline \multicolumn{6}{|l|}{ Weight } \\
\hline$<69 \mathrm{~kg}$ & 33 & 30.8 & 21 & 19.7 & \multirow[t]{2}{*}{$0.033^{*}$} \\
\hline$\geq 69 \mathrm{~kg}$ & 43 & 40.2 & 10 & 9.3 & \\
\hline \multicolumn{6}{|l|}{ Height } \\
\hline$<1,78 \mathrm{~m}$ & 39 & 36.4 & 18 & 16.8 & \multirow[t]{2}{*}{0.67} \\
\hline$\geq 1,78 \mathrm{~m}$ & 37 & 34.6 & 13 & 12.2 & \\
\hline \multicolumn{6}{|l|}{ BMI } \\
\hline$<$ Ideal & 13 & 12.1 & 5 & 4.7 & \multirow[t]{4}{*}{0.77} \\
\hline Ideal & 58 & 54.2 & 26 & 24.3 & \\
\hline$>$ Ideal & 5 & 4.7 & - & - & \\
\hline Total & 76 & 71 & 31 & 29 & \\
\hline
\end{tabular}

\section{Factors related to sport activity}

The study assessed associations between; the sport type, the category of athletes, the profile, the regularity in practice, the years of practice, the preparation, the warming up and the stretching before physical exercises and the ankle sprain. All factors were found not statically significant except for the type of sport $(p=0.038)$ and the profile of the athlete $(p=0,006)$.

Table 3 depicts the full results. The $p$ values for each factor are presented as well. 
Table 3

Sport data for injured and uninjured athletes

\section{Injured Uninjured}
(n)
(\%)
(n)
(\%) $P$

Sport type

$\begin{array}{llllll}\text { Basketball } & 25 & 23.4 & 4 & 3.7 & 0.038^{*}\end{array}$

$\begin{array}{lllll}\text { Football } & 14 & 13.1 & 6 & 5.6\end{array}$

$\begin{array}{lllll}\text { Handball } & 12 & 11.2 & 4 & 3.7\end{array}$

$\begin{array}{lllll}\text { Running } & 15 & 14 & 8 & 7.5\end{array}$

$\begin{array}{lllll}\text { Tennis } & 8 & 7.5 & 5 & 4.7\end{array}$

$\begin{array}{lllll}\text { Volleyball } & 2 & 1.9 & 4 & 3.7\end{array}$

Category

$\begin{array}{llllll}\text { Cadet } & 38 & 35.5 & 13 & 12.1 & 0.301\end{array}$

$\begin{array}{lllll}\text { Junior } & 15 & 14 & 5 & 4.7\end{array}$

$\begin{array}{lllll}\text { Senior } & 23 & 21.5 & 13 & 12.2\end{array}$

Profile

$\begin{array}{llllll}\text { Amateur } & - & - & 3 & 2.8 & 0.006^{*}\end{array}$

$\begin{array}{lllll}\text { Competitor } & 76 & 71 & 28 & 26.2\end{array}$

Regularity of practice

$\begin{array}{llllll}\text { Rgular } & 74 & 69.1 & 28 & 26.2 & 0.145\end{array}$

$\begin{array}{lllll}\text { Non regular } 2 & 1.9 & 3 & 2.8\end{array}$

Years of practice

$\left[\begin{array}{llllll}{[1,2[} & 3 & 2.8 & 2 & 1.9 & 0,654\end{array}\right.$

$\left[2,5\left[\begin{array}{lllll}24 & 22.4 & 10 & 9.3\end{array}\right.\right.$

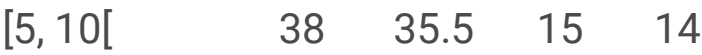

$\begin{array}{lllll}\geq 10 & 11 & 10.3 & 4 & 3.7\end{array}$

Preparation

$\begin{array}{llllll}\text { Yes } & 74 & 69.1 & 28 & 26.2 & 0,145\end{array}$

$\begin{array}{lllll}\text { No } & 2 & 1.9 & 3 & 2.8\end{array}$

*; difference statically significant 


\begin{tabular}{|l|lllllll|}
\hline \multicolumn{7}{|c|}{ Injured } & Uninjured \\
\hline Warming up & & & & \\
\hline$\geq 10$ min & 67 & 62.6 & 26 & 24.3 & 0.755 \\
$<10$ min & 9 & 8.4 & 5 & 4.7 & \\
\hline Stretching & & & & & \\
\hline Yes & 41 & 38.3 & 16 & 15 & 0.834 \\
No & 35 & 32.7 & 15 & 14 & \\
\hline Total & 76 & 71 & 31 & 29 & \\
\hline *; difference statically significant & & \\
\hline
\end{tabular}

\section{Foot intrinsic factors}

The foot examination revealed a significant differences between groups in terms of unipodal static balance $(p<0.05)$, dorsiflexion mobility $(p<0.05)$ and ankle instability $(p<0.05)$.

Table 4 depicts the full results. The $p$ values for each factor are presented as well. 
Table 4

Podiatric data for injured an uninjured athletes

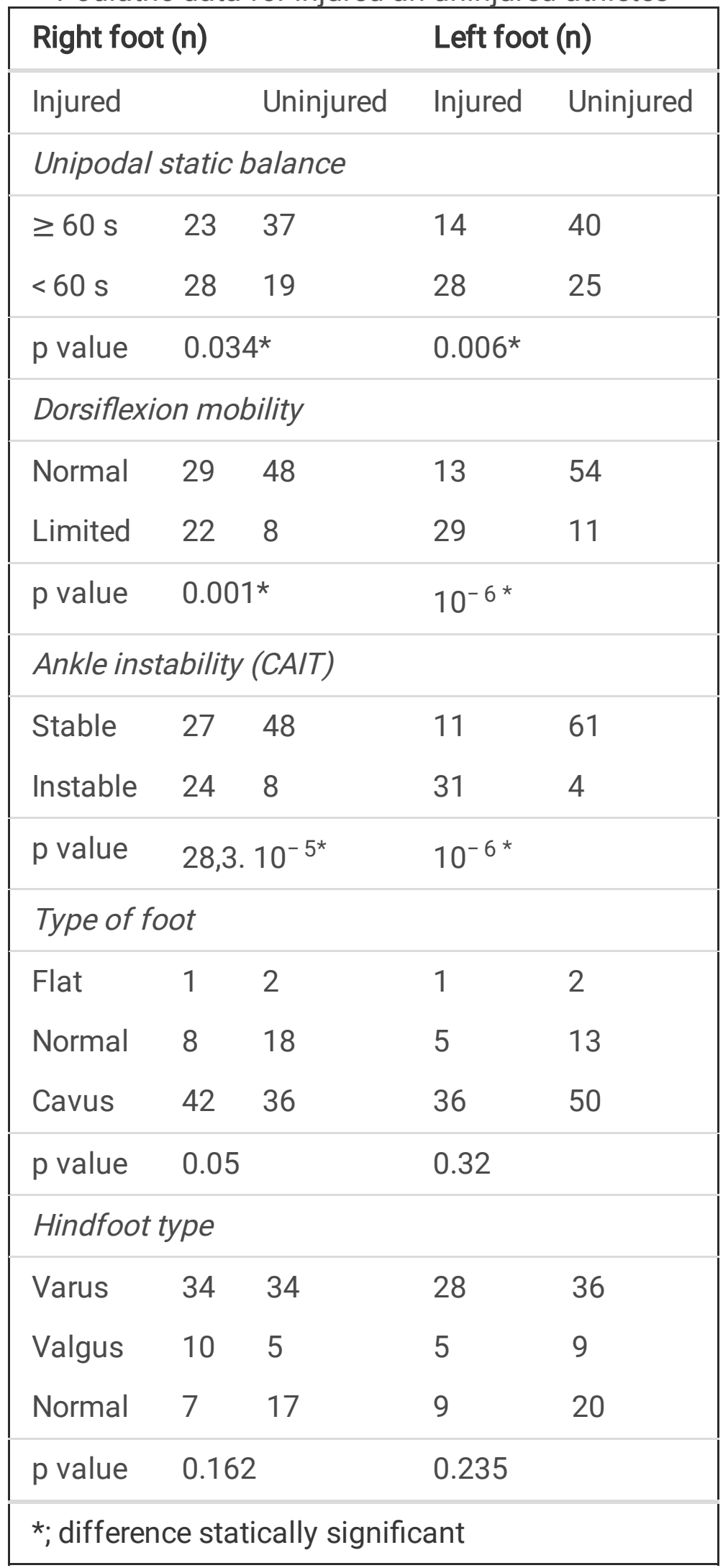

The examination of the muscular force revealed that the athletes with injured ankle had more limitations than those who are not affected. Indeed, a significant difference between groups were found in the long tibial muscle $(p<0.05)$ and the posterior tibial muscle $(p<0.05)$. 
Table 5 depicts the full results. The $p$ values for each factor are presented as well.

Table 5

Muscular force data for injured and uninjured athletes

\begin{tabular}{|c|c|c|c|c|}
\hline \multicolumn{3}{|c|}{ Right Ankle (n) } & \multicolumn{2}{|c|}{ Left Ankle (n) } \\
\hline Injured & & Uninjured & Injured & Uninjured \\
\hline \multicolumn{5}{|c|}{ Limitation of the long fibular } \\
\hline Limited & 16 & 5 & 15 & 6 \\
\hline Normal & 35 & 51 & 25 & 59 \\
\hline$p$ value & 0.0 & & $0.002^{*}$ & \\
\hline \multicolumn{5}{|c|}{ Limitation of posterior tibial } \\
\hline Limited & 14 & 5 & 15 & 8 \\
\hline Normal & 37 & 51 & 27 & 57 \\
\hline$p$ value & \multicolumn{2}{|c|}{$0.026 *$} & \multicolumn{2}{|l|}{$0.027 *$} \\
\hline
\end{tabular}

\section{- Ligament laxity}

We found that the ligament laxity was statistically significant. The anterior drawer test and the varus stress test showed a statistically significant difference $p=10^{-6}$ for the left and right ankle.

The valgus stress test was significant only for the left ankle $p=0,021$.

\section{Discussion}

\section{Prevalence}

Our study showed that the ankle sprain affected $71 \%$ of our sample. This percentage was lower to the study conducted by Karen G. Roos et al, in which the prevalence of ankle sprains in National Collegiate Athletic Association Sports was 95\% [14]. However, another study showed that ankle sprains represented $15 \%$ of injuries occurring in the field of sport [1]. These differences between the results can be explained by methodological difference such as; sampling techniques or the characteristics of the different groups in different contexts or even to the negligence of athletes of the preventive measures of ankle sprains, hence its high frequency.

\section{Ankle sprain}


As for the location of ankle sprains, we noted that unilateral injury was more frequent (77.6\%) compared to bilateral injury (22.4\%). This can be explained by the fact that ankle sprains frequently affect the dominant member of the athlete. According to Ekstrand and Gillquist jan, the risk of ankle injuries increases in the dominant member [15].

The male population was more affected by ankle sprains (64.5\%). Our results were comparable to those found in a study by Karen G. Roos et al. In fact, they demonstrated that the exposure to ankle sprains in men was higher than women [14]. The low vulnerability of women can be explained by their flexibility and by the practise of less offensive and lower risks sports.

The percentage of ankle sprains in athletes also varied according to the type of sport practised; it decreases from Basketball (86.2\%) to Handball (75\%), then Football (70\%), Running (65.2\%), Tennis (61.5\%) and finally Volleyball (33.3\%). A study by Romain Terrier et al. reported results comparable [16]. These results can be explained by the facts that Basketball contains a lot of movements of brutal reception of the foot during parachute jumps that can cause a bascule of the foot in inversion or eversion cause though ankle sprains.

Based on our findings, cadets were the most affected category with ankle sprains (47.6\%) compared to seniors (33.3\%) and juniors (18.7\%). These results can be explained, on one hand by the fact that cadets do not yet master the technical gestures. On the other hand by the fact, that seniors have usually a training rhythm more intense than cadets and juniors which can increase the rate of exposure.

All the athletes with ankle sprains were competitors. This result was similar to the one observed in a study conducted by Yeung Mphil et al. who were interested in competitor athletes [17]. Therefore, the high frequency of training hours and the intensive rhythm for competitors can generate a hyper- extensibility of the ankle ligaments and solicit them which can make the ankle more at risk of developing sprains compared to amateurs that usually practise sport for leisure and just to stay in shape.

\section{Associated factors}

Regarding anthropometric data; the results showed that no statistically significant difference was observed for age, gender, height and body mass index. However, weight was shown to be statistically significant with ankle sprain $(p=0.033)$. A study conducted by Bruce $D$ et al. on 118 college athletes demonstrated that height and weight were not related to ankle sprains [5]. These results can be explained by the fact that the majority of our athletes have normal body mass indexes. Thus, we cannot resume if there is an association between the ankle sprain and excess of weight.

Concerning sports data, our results demonstrated that ankle sprain was associated to the type of sport practiced $(p=0,038)$ and to the profile of the athlete $(p=0,006)$. Indeed, the characteristics of all type of sports included in this study, solicit the ankle and its different compositions. Hence, the occurrence of ankle sprains. 
According to Bruce D, Beynnon et al., the type of foot and the type of the hindfoot are not associated to the incidence of ankle sprain [5]. Likewise, Dahle et al.[18] and Barrett et al. [19] reported no correlation between anatomic foot type (pronated, neutral, or supinated) and the incidence of ankle sprains. Our results support these findings.

Regarding unipodal static balance, the majority of the athletes affected with ankle sprains had an alteration of the unipodal balance compared to those not affected. This association was found statistically significant with $p<0.05$. This fact can be explained by the alteration of the ligaments that stabilize the ankle joint which can be responsible for static disorders.

In our study, the ankle instability was associated to ankle sprains. Indeed, residual ligament laxity can result in the loss of the joint stability. Therefore, the athlete may feel insecure. According to Thomas Bauer, ankle instability is the main sequelae that patients complain about after ankle sprains [20].

Regarding muscular force, only the long fibular and the posterior tibial muscles were found statically significant. These results can be explained by the fact that the eversers are the lateral stabilizing muscles of the ankle. During a sudden reversal movement, the weakened ones will not stabilize the ankle and they will let it roll up. However, the athlete may previously have a weakness of the muscles which would leave the ankle unstable and can lead to the occurrence of ankle sprains.

\section{Limitations}

The current study was conducted only in the region of Sousse. Hence the results cannot be generalized to the general population and also should be carefully interpreted.

In this study, we used a self-administrated questionnaire in order to assess ankle instability. However, questionnaires can be subjective and this can lead to an over or underestimation of the results.

Mmissing data on medical records of athletes were one of the most limitations that we have faced during the realization of this study. However, some medical questions were asked directly to the attending physician in order to fill the missing data.

\section{Conclusion And Implications For Practice}

Ankle sprain is a frequent trauma in the sports field. Often benign, however it should not be overlooked because of its frequent recurrence, the potential painful sequelae and the risk of instability that it can cause. All of these manifestations have a negative impact on the athlete's performance.

For this major reason, this injury has aroused the interest of several researchers in the field of health and sport sciences seeking to explore it and identify the factors leading to its occurrence.

This research can enable healthcare professionals and sportsmen to better understand factors that can lead to ankle sprains. In fact, the main associated factors highlighted in this study must be taken into consideration in order to prevent these injuries and to improve sportsmen's performance. 
This study will help physicians and fitness trainers to design appropriate programs fitted to reduce the incidence of ankle sprains.

The information gained from the study will contribute to the education of podiatry students in Tunisia regarding ankle sprains prevention during clinical practice.

\section{Abbreviations}

- CAIT: Cumberland Ankle Instability Tool

- BMI: body mass index.

\section{Declarations}

\section{- Ethics approval and consent to participate}

The consent of the committee of research in the Higher School of Health Sciences and Techniques of Sousse was taken before the beginning of the study.

The presidents of the sports associations authorized the study.

An authorization was granted from the corresponding author in order to use the French version of the CAIT questionnaire.

Prior to data collection, consent of the athletes was obtained after being informed about the objectives, the conditions of the study and the tests to be performed as well as the utility of the questionnaire in a concrete way and understandable words.

Participants were informed about their rights to participate, to refuse and to withdraw at any time. Anonymity and confidentiality were guaranteed by using a digital identifier assigned to each file.

\section{- Consent for publication}

Not applicable.

\section{- Availability of data and materials}

The datasets used and/or analyzed during the current study are available from the corresponding author on reasonable request.

\section{- Competing interests}

The authors declare that there is no conflict of interest regarding the publication of this paper. 


\section{- Funding}

No funding was obtained for the preparation of this article.

\section{- Authors' contributions}

ET and FK conceived and administered the study. MG and HM carried out the data collection and got ethics approval and consent from associations and participants. ET participated in the design of the study and performed the statistical analysis. MG prepared the preliminary version of the manuscript and translated the original manuscript from French to English. ET participated in the correction and the reviewing of the draft of the current version with the help of FK. All authors contributed substantially to review the manuscript. The authors read and approved the final manuscript.

\section{- Acknowledgments}

The authors would like to thank all Springer Nature Team for their support and help, Also we would like to thank all participants and the presidents of the 6 associations for their cooperation. We are grateful to Meriam TAGHOUTI for her valuable comments during the realization of this manuscript

\section{References}

1. Eils E, Schröter R, Schroeder M, S JG, Rosenbaum D. Multistation proprioceptive exercise program prevents ankle injuries in basketball. Med Sci Sports Exerc. 2010;42:2098-105. https://doi.org/10.1249/MSS.0b013e3181e03667.

2. Vosseller JT, Karl JW, Greisberg JK. Incidence of syndesmotic injury. Orthopedics. 2014.

3. Shah S, Thomas AC, Noone JM, Blanchette CM, Wikstrom EA. Incidence and Cost of Ankle Sprains in United States Emergency Departments. Sports Health. 2016.

4. Gerber JP, Williams GN, Scoville CR, Arciero RA, Taylor DC. Persistent disability associated with ankle sprains: A prospective examination of an athletic population. Foot Ankle Int. 1998.

5. Beynnon BD, Renström PA, Alosa DM, Baumhauer JF, Vacek PM. Ankle ligament injury risk factors: a prospective study of college athletes. J. 2001;19:213-20. https://doi.org/10.1016/S07360266(00)90004-4. OrthopRes .

6. Miguel Ângelo de Castro C, João T. Intrinsic and Extrinsic Risk Factors for Lateral Ankle Sprain: A Literature Review. Arch Sport Med. 2019. https://doi.org/10.36959/987/247.

7. Geerinck A, Beaudart C, Salvan Q, Van Beveren J, D'Hooghe P, Bruyère O, et al. French translation and validation of the Cumberland Ankle Instability Tool, an instrument for measuring functional ankle instability. Foot Ankle Surg. 2020.

8. Hiller CE, Refshauge KM, Bundy AC, Herbert RD, Kilbreath SL. The Cumberland Ankle Instability Tool: A Report of Validity and Reliability Testing. Arch Phys Med Rehabil. 2006;87:1235-41. https://doi.org/10.1016/j.apmr.2006.05.022. 
9. Miranda CHA, Cu LAF, López SC, González HR, Lara MC. Interface for Contour Extraction and Determination of Morphologic Parameters in Digital Images of Footprints Based on Hernandez-Corvo Protocol. In: IFMBE Proceedings. 2020. https://doi.org/10.1007/978-3-030-30648-9_48.

10. Gutiérrez-Vilahú L, Massó-Ortigosa N, Costa-Tutusaus L, Guerra-Balic M. Reliability and Validity of the Footprint Assessment Method Using Photoshop CS5 Software. J Am Podiatr Med Assoc. 2015;105:226-32. https://doi.org/10.7547/0003-0538-105.3.226.

11. Springer BA, Marin R, Cyhan T, Roberts H, Gill NW. Normative values for the unipedal stance test with eyes open and closed. J Geriatr Phys Ther. 2007.

12. Bohannon RW, Tudini F. Unipedal balance test for older adults: a systematic review and metaanalysis of studies providing normative data. Physiotherapy (United Kingdom). 2018. https://doi.org/10.1016/j.physio.2018.04.001.

13. Hengeveld E, Banks K. Maitland's Peripheral Manipulation. Vol. 2. Edinburgh: Churchill Livingstone; 2014.

14. Roos KG, Kerr ZY, Mauntel TC, Djoko A, Dompier TP, Wikstrom EA. The Epidemiology of Lateral Ligament Complex Ankle Sprains in National Collegiate Athletic Association Sports. Am J Sports Med. 2017.

15. Ekstrand J, Gillquist J. Soccer injuries and their mechanisms: a prospective study. Med Sci Sports Exerc. 1983;15:267-70.

16. Terrier R, Gédor C, Toschi P, Forestier N. Caractérisation de la prise en charge de l'entorse latérale de cheville chez une population de jeunes sportifs. Kinésithérapie Rev. 2013;13:11-5. https://doi.org/10.1016/j.kine.2012.05.022.

17. Yeung MS, Chan KM, So $\mathrm{CH}$, Yuan WY. An epidemiological survey on ankle sprain. Br J Sports Med. 1994;28:112-6. https://doi.org/10.1136/bjsm.28.2.112.

18. Dahle LK, Mueller M, Delitto A, Diamond JE. Visual Assessment of Foot Type and Relationship of Foot Type to Lower Extremity Injury. J Orthop Sports Phys Ther. 1991;14:70-4.

19. Barrett JR, Tanji JL, Drake C, Fuller D, Kawasaki RI, Fenton RM. High- versus low-top shoes for the prevention of ankle sprains in basketball players: A prospective randomized study. Am J Sports Med. 1993;21:582-5. https://doi.org/10.1177/036354659302100416.

20. Bauer T. Les entorses de la cheville et leurs séquelles. Rev Rhum Monogr. 2014;81:162-7. https://doi.org/10.1016/j.monrhu.2014.04.014. 